\title{
The direct and legacy effects of drying-rewetting cycles on active and relatively resistant soil carbon decomposition
}

\author{
Shuai Zhang ${ }^{1}$, Junjie Lin $^{2}$, Peng Wang ${ }^{3}$, and Biao Zhu ${ }^{4}$ \\ ${ }^{1}$ Zhejiang University \\ ${ }^{2}$ Chongqing Three Gorges University \\ ${ }^{3}$ c. Key Laboratory of Forest Ecology and Management, Institute of Applied Ecology \\ ${ }^{4}$ Peking University
}

November 9, 2021

\begin{abstract}
Global climate change is expected to increase the frequency of drought and heavy precipitation, which could create more frequent drying-rewetting cycles (DWC) in the soils. Although DWC effects on SOC decomposition has been widely studied, the effect of DWC and the subsequent legacy effect on the decomposition of different SOC pools is still unclear. We conducted a 128-d laboratory incubation to investigate the DWC effects by using soils from old-field for 15 years (OF, representing active $\mathrm{SOC}$ ), bare-fallow for 15 years $(\mathrm{BF})$, and bare-fallow for 23 years plus extra 815-d incubation (BF+, representing relatively resistant SOC). The experiment included nine 10-d DWC of three treatments: 1) constant-moisture at $60 \%$ WHC, 2) mild DWC with 10 -d drying to $40 \%$ WHC and rewetting to $80 \%$ WHC, and 3) strong DWC with 10 -d drying to $20 \%$ WHC and rewetting to $100 \%$ WHC. Following DWC period, there was a 10-d stabilization period (adjusting all treatments to $60 \%$ WHC), and then a 28-d extended incubation. During DWC period, the strong DWC had strong effect on CO2 release compared with the constant-moisture control, reducing the SOC decomposition from OF by $8 \%$ and $\mathrm{BF}$ by $10 \%$, while increasing the SOC decomposition of $\mathrm{BF}+$ by $16 \%$. During extended period, both mild and strong DWC significantly increased SOC mineralization of $\mathrm{OF}$, but decreased that of $\mathrm{BF}$ and $\mathrm{BF}+$. This legacy effect compensated the changes in $\mathrm{CO} 2$ release during DWC period, resulting in the minor response of $\mathrm{SOC}$ decomposition of $\mathrm{OF}$ and $\mathrm{BF}+$ to the $\mathrm{DWC}$ during the entire incubation.
\end{abstract}

The direct and legacy effects of drying-rewetting cycles on active and relatively resistant soil carbon decomposition

Shuai Zhang ${ }^{\mathrm{a}, \mathrm{b}}$, Junjie Lin ${ }^{\mathrm{a}^{*}}$, Peng Wang ${ }^{\mathrm{c}}$, Biao Zhu ${ }^{\mathrm{d}^{*}}$

1. Chongqing Key Laboratory of Water Environment Evolution and Pollution Control in Three Gorges Reservoir, Chongqing Three Gorges University, Chongqing 404100, China

2. College of environmental and resource sciences, Zhejiang University, Hangzhou, Zhejiang 310058, China

3. Key Laboratory of Forest Ecology and Management, Institute of Applied Ecology, Chinese Academy of Sciences, Shenyang 110016, China

4. Institute of Ecology, College of Urban and Environmental Sciences, and Key Laboratory for Earth Surface Processes of the Ministry of Education, Peking University, Beijing 100871, China

*Corresponding authors: Dr. Junjie Lin and Dr. Biao Zhu

E-mail addresses:junjielin@sanxiau.edu.cn(J. Lin) and biaozhu@pku.edu.cn(B.Zhu)

Abstract: Global climate change is expected to increase the frequency of drought and heavy precipitation, which could create more frequent drying-rewetting cycles (DWC) in the soils. Although the DWC effects on soil organic carbon (SOC) decomposition has been widely studied, the effect of DWC and the subsequent 
legacy effect on the decomposition of different SOC pools is still unclear. We conducted a 128-d laboratory incubation to investigate the DWC effects by using soils from old-field for 15 years (OF, representing active $\mathrm{SOC}$ ), bare-fallow for 15 years (BF), and bare-fallow for 23 years plus extra 815-d incubation (BF+, representing relatively resistant SOC). The experiment included nine 10-d DWC of three treatments: 1) one mean constant-moisture at $60 \%$ water-holding capacity (WHC), 2) a mild DWC with 10-d drying to $40 \%$ WHC and immediately rewetting to $80 \%$ WHC, and 3) a strong DWC with 10 -d drying to $20 \%$ WHC and immediately rewetting to $100 \%$ WHC. Following the DWC period $(0-90 \mathrm{~d})$, there was a 10-d stabilization period (adjusting all treatments to $60 \% \mathrm{WHC}$ ), and then a $28-\mathrm{d}$ extended incubation under the constant moisture of $60 \%$ WHC. During the DWC period, the strong DWC had a strong effect on $\mathrm{CO}_{2}$ release compared with the constant-moisture control, reducing the SOC decomposition from OF by $8 \%$ and BF by $10 \%$, while increasing the SOC decomposition of $\mathrm{BF}+$ by $16 \%$. In addition, during the extended period, both mild and strong DWC significantly increased SOC mineralization of OF, but decreased that of $\mathrm{BF}$ and $\mathrm{BF}+$. This legacy effect induced by DWC compensated the changes in $\mathrm{CO}_{2}$ release during the DWC period, resulting in the minor response of SOC decomposition of $\mathrm{OF}$ and $\mathrm{BF}+$ to the DWC during the entire incubation. Together, DWC could create both direct and legacy effects, and these effects vary with DWC intensity and SOC pools.

Keywords : Drying-rewetting; Soil carbon pool; Soil organic matter; Soil respiration; Legacy effect

Abbreviations : DWC - drying-rewetting cycles; OF - old-field; $\mathrm{BF}$ - bare-fallow; $\mathrm{BF}+$ - bare-fallow + incubation; $\mathrm{C}$ - carbon; $\mathrm{CO}_{2}$ - carbon dioxide; $\mathrm{SOC}$ - soil organic carbon; $\mathrm{MBC}$ - microbial biomass carbon; DOC - dissolved organic carbon; TC - total carbon; $\mathrm{TN}$ - total nitrogen; $\mathrm{C} / \mathrm{N}$ - the ratio of carbon to nitrogen; $\mathrm{F}: \mathrm{B}$ - the ratio of fungi to bacteria.

\section{Introduction}

Global climate models predict increases in atmospheric carbon dioxide $\left(\mathrm{CO}_{2}\right)$ concentration and surface temperature (IPCC, 2013), which are likely to alter regimes of global hydrologic cycling, including an increase in the number and severity of droughts and heavier precipitation between drought periods (Dai, 2013; Donat et al., 2016). Soil moisture is a key factor controlling the microbial decomposition of soil organic carbon (SOC) (Moyano et al., 2013). When the soil is dry, microbial activity and substrate diffusion will be restricted, and soil respiration will be reduced (Schimel, 2018). The rapid precipitation after drought usually increases mineralization of SOC, creating a large pulse of $\mathrm{CO}_{2}$ (Birch, 1958; Kim, et al., 2012). The $\mathrm{CO}_{2}$ pulse has been attributed to the rapid consumption of microbial necromass as available substrates and released microbial osmoregulatory substances in response to water stress (Blazewicz et al., 2014; Chowdhury et al., 2019; Warren, 2016). In addition, the sudden influx of water at rewetting can expose previously inaccessible carbon (C) to microorganisms through aggregates breakdown (Denef et al., 2001; Najera et al., 2020; Schimel et al., 2011). This rewetting-driven $\mathrm{CO}_{2}$ pulse can be sustained for more than 20 days (Canarini et al., 2017) and elevated by as much as $475 \%$ relative to a constant-moisture soil (Fierer and Schimel, 2003). Therefore, soil drying-rewetting cycles (DWC) are considered an essential environmental factor regulating C cycle in terrestrial ecosystems (Borken and Matzner, 2009; Fierer and Schimel, 2002; Muhr et al., 2008; Schimel, 2018; Zhu and Cheng, 2013).

Although a large number of studies have examined the effects of DWC on soil C decomposition, DWC increased (Butterly et al., 2009; Miller et al., 2005; Shi and Marschner, 2014; Xiang et al., 2008; Yemadje et al., 2017), decreased (Shi and Marschner, 2014), or did not change (Yemadje et al., 2017) cumulative $\mathrm{C}$ decomposition relative to constant-moisture control in previous studies. Zhang et al. (2020) indicated in a recent meta-analysis that relative to a constant-moisture control (with the same mean value), the rewetting-driven $\mathrm{CO}_{2}$ pulse can fully compensate the reduced $\mathrm{CO}_{2}$ emission during the drying phase, thus DWC did not change cumulative $\mathrm{C}$ decomposition. They also commented that the changes in cumulative $\mathrm{C}$ loss depend on DWC intensity. Intensified drought usually triggers a stronger $\mathrm{CO}_{2}$ pulse after rewetting (Barnard et al., 2015; Li et al., 2018), because a severer drought may lead to a higher frequency of microbial death and accumulate more compatible solutes, which can contribute largely to the $\mathrm{CO}_{2}$ pulse (Barnard et al., 2020; Guo et al., 2012). Moreover, there may be a drought threshold, beyond which the inaccessible C 
will be accessed, thereby contributing to the subsequent $\mathrm{CO}_{2}$ pulse (Canarini et al., 2017; Homyak et al., 2018). Moreover, DWC can promote the release of old $\mathrm{C}$ that had been occluded in soils for more than 600 years (Schimel et al., 2011). However, due to the difficulties in separation of decomposition of SOC pools with different turnover times, few studies have evaluated the vulnerability of different SOC pools to DWC. Therefore, due to the large proportion of stable $\mathrm{C}$ in the total soil $\mathrm{C}$ pool, clarifying its response to climate change is essential for predicting future changes in the global $\mathrm{C}$ cycle.

Soil organic carbon can be divided into three pools with different physiochemical characteristics and turnover times (Davidson and Janssens, 2006; Lin et al., 2015). The most active fraction is annually cycling, active SOC, which mainly consists of microbial biomass and plant detritus, and has a fast turnover time from weeks to years, contributing to approximately $0 \sim 5 \%$ of the total SOC pool (Parton et al., 1987; Semenov et al., 2018). It hardly contributes much to the global $\mathrm{C}$ cycle due to its small size and very fast turnover time. The most inert fraction is millennially cycling, passive (inert) SOC, which is mainly composed of black carbon or humic substances and has a turnover time even more than centuries, accounting for about $10 \sim 40 \%$ of the total SOC pool (Schmidt et al., 2011). Furthermore, the more critical pool is the decadally cycling, relatively resistant (intermediate, slow) SOC, which is the dominant component of the total SOC pool, accounting for around $60 \sim 80 \%$ of the total SOC pool, and has a turnover time of decades. It is generally believed that different microbial communities use different soil substrates (Berg and McClaugherty, 2008; $\mathrm{Xu}$ et al., 2015), and bacteria are considered more responsible for consuming readily available substrates (Moore-Kucera and Dick, 2008), while fungi are believed to have the ability to decompose more stable SOC (Xu et al., 2015). Fungi display an overall higher resistance to drying and subsequent rewetting processes than bacteria (Barnard et al., 2015; Yuste et al., 2011). As a consequence, relatively resistant SOC may be more susceptible to DWC due to the higher resistance of fungi to drought and thus the smaller reduction in C decomposition during the drying process (de Vries et al., 2018; Zhang et al., 2020).

Furthermore, previous conditions can affect current processes, which is called the legacy effect (Monger et al., 2015). The DWC-driven legacy effect can compensate for $14 \%$ of the decrease of cumulative C decomposition during the DWC period (Li et al., 2018). However, the legacy effect of DWC on the decomposition of different SOC pools remains unclear. Thus, the direct and legacy effects of DWC on SOC pools with different turnover times remain uncertain and require further investigation.

To fill this knowledge gap, we use soils from three plots in a long-term experimental field to explore the direct and legacy effects of DWC on active and relatively resistant soil $\mathrm{C}$ decomposition. In our study, the direct effect represents the effect of DWC on $\mathrm{C}$ decomposition in the DWC period, and the legacy effect denotes the effect of previous DWC on C decomposition in the post-DWC incubation period with constant moisture. We conducted a laboratory incubation experiment of 128 days, combining three water regimes, nine 10-d DWC (in a row) and one 28-d extended period, to investigate the direct and legacy effects of DWC on active and relatively resistant soil $\mathrm{C}$ decomposition. We hypothesized that (i) compared to the constant-moisture control, the DWC with intensified drought would stimulate more $\mathrm{C}$ emission during the entire drying-rewetting period due to the strong $\mathrm{CO}_{2}$ pulse after rewetting; (ii) the relatively resistant SOC (the bare-fallow and the bare-fallow+incubation soils) would be more vulnerable to DWC than the active SOC (the old-field soil) due to the higher resistance of fungi in the relatively resistant SOC to DWC; and (iii) the DWC could create a legacy effect on soil C decomposition due to the changes in microbial biomass and labile substrates.

\section{Materials and methods}

\subsection{Site description and soil sampling}

Soils were sampled from a long-term experimental field located in the Shenyang station of Chinese Academy of Sciences, Liaoning province, Northeastern China (41 $32^{\prime}$ N, 122deg23' E). The climate is typical continental monsoon, with a mean annual temperature of $7.9 \mathrm{degC}$ and mean annual precipitation of $604 \mathrm{~mm}$ (1981-2018,https://power.larc.nasa.gov). The long-term old-field (OF) and bare-fallow (BF) treatments were established in 2003 and were paddy fields before treatments. The OF plot received fresh organic input for 
15 years (2003-2018) with freely growing weeds but no anthropogenic interference. The BF plot was kept free of organic input for 15 years (2003-2018) by frequent hand weeding. Soils from these OF and BF treatments were sampled in 2018. Another BF plot had been kept free of organic input for 23 years until soil sampling for this study (Zhang et al., 2021). Soils were collected from the plow layer $(0-20 \mathrm{~cm}$ depth) in the long-term experimental field. Within each plot, soils were sub-sampled at five randomly selected sites and then homogenized into one sample. Prior to the incubation experiment, soil samples were air-dried, sieved to $2 \mathrm{~mm}$, and homogenized thoroughly. Visible roots, plant detritus, and stones were removed carefully by handpicking.

\subsection{Experimental design and soil incubation}

The soil from the OF treatment (15 year-old) represents active SOC. The soils from the BF treatment for 15 years and $\mathrm{BF}$ treatment for 23 years plus an extra 815 days of laboratory incubation (BF+, the additional incubation is to further consume active organic carbon) represent relatively resistant SOC (Zhang et al., 2017). Therefore, we refer to the $\mathrm{OF}$ SOC as active $\mathrm{C}$, the $\mathrm{BF}$ and the $\mathrm{BF}+\mathrm{SOC}$ as relatively resistant $\mathrm{C}$ in this study. Although all three soils may still contain various components with different turnover times and protection mechanisms, here we operationally used the three soils to represent active and relatively resistant SOC (Conant et al., 2008; Townsend et al., 1997), and compared the relative vulnerability of these SOC pools to the direct and legacy effects of drying-wetting cycles for two reasons. First, we measured the proportion of active $\mathrm{C}$ (dissolved organic carbon/total carbon, DOC/TC) and found that the proportion of active $\mathrm{C}$ in the $\mathrm{OF}$ soil is the highest, and that in the $\mathrm{BF}+$ soil is the lowest (Table 1). Second, we measured the chemical composition of SOC of these three soils and found that the molecular index of SOC stability (or resistance) in the $\mathrm{OF}$ soil is the lowest, and that in the $\mathrm{BF}+$ soil is the highest (Fig. 2). In addition, Barre et al. (2010) constrained a three-pool-model using observed soil organic $\mathrm{C}$ data in long-term BF soils and found that most of the organic $\mathrm{C}$ are stable $\mathrm{C}$ (turnover time of several centuries or more). Basic properties of these three soils can be found in Table 1 and Zhang et al. (2017).

The incubation experiment consisted of a nine 10-d DWC period and a 28-d extended period, with a 10-d stabilization period between them (Fig. 1). In the DWC period (0-90 d), soils were subjected to three water regimes, including one constant-moisture control (mean moisture content: 60\% WHC), one mild DWC treatment (80-40\% WHC), and one strong DWC treatment (100-20\% WHC), each with three replicates. After the 90-d DWC period, all treatments were adjusted to constant moisture of $60 \%$ WHC for ten days to a consistent state (90-100 d). All soils were kept at $60 \%$ WHC during the subsequent 28-d extended period $(100-128 \mathrm{~d})$.

For each soil, a subsample of $60 \mathrm{~g}$ (dry weight basis) was placed in a 1-L incubation jar at $60 \%$ WHC with deionized water, and the soils were pre-incubated at $22 \mathrm{degC}$ for 10 days in the dark. To achieve soil drying, $45 \mathrm{~g}$ and $20 \mathrm{~g}$ silica gel were placed in the incubation jars for 100-20\% WHC and $80-40 \%$ WHC treatments, respectively (Fig. S1). These two weights were chosen because our pre-experimental data showed that these two weights of silica gel could accelerate the loss of soil moisture to the expected levels (i.e. $20 \%$ and $40 \%$ WHC) in 10 days. Inside each jar, $10 \mathrm{ml} 0.5 \mathrm{M} \mathrm{NaOH}$ solution was used to trap $\mathrm{CO}_{2}$ from SOC decomposition. At the end of each drying period, the $\mathrm{NaOH}$ solution and silica gel were replaced, and the soil samples were rapidly rewetted by adding deionized water with a syringe. The trapped $\mathrm{CO}_{2}-\mathrm{C}$ in the $\mathrm{NaOH}$ solutions were immediately measured in the form of total inorganic $\mathrm{C}$ using a Lotix combustion TOC analyzer (Teledyne Tekmar, USA), and the silica gel was dried in an oven at $105 \mathrm{degC}$ overnight to regenerate it. After replacing the silica gel and $\mathrm{NaOH}$ solution, the jars were sealed immediately with gas-tight lids and kept at $22 \mathrm{deg} \mathrm{C}$ in the dark. A previous study proved that silica gel does not absorb $\mathrm{CO}_{2}$ (Harrison-Kirk et al., 2013). Three blanks without soil were incubated at the same condition to quantify the amount of $\mathrm{C}$ in the air and initial $\mathrm{NaOH}$ solution. Prior to measuring the total inorganic $\mathrm{C}$, the $\mathrm{NaOH}$ solutions in the DWC treatments were adjusted back to $10 \mathrm{ml}$ with deionized water.

After the 90-d DWC period, all soils were adjusted to a constant moisture content of $60 \%$ WHC and maintained for 10 days (stabilization period, 90-100 d). Note that we did not measure respiration for the stabilization period. On day 100, we did a destructive soil sampling. Specifically, $8 \mathrm{~g}$ subsamples were used 
to determine dissolved organic carbon (DOC) and microbial biomass carbon (MBC), $10 \mathrm{~g}$ subsamples were stored at $-80 \mathrm{degC}$ until the measurement of microbial biomass, and $10 \mathrm{~g}$ subsamples were incubated for another $28 \mathrm{~d}$ (extended period, 100-128 d) in which the $\mathrm{CO}_{2}$ - $\mathrm{C}$ in the $\mathrm{NaOH}$ solutions were measured on day $103,107,114,121$ and 128.

In total, we incubated 30 jars $((3 \times 3+1) \times 3)$ consisting of three soils (OF, BF and $\mathrm{BF}+$ soils), two DWC treatments (100-20\% and 80-40\% WHC) and one constant-moisture control treatment (60\% WHC), one blank, and three replicates for each treatment.

\subsection{Soil property analyses}

Soil total C and N (nitrogen) contents were measured using an elemental analyzer (EA 3000, Euro Vector, Milan, Italy). The $\mathrm{pH}$ was measured in a 1:2.5 soil-water ratio with a $\mathrm{pH}$ meter (PHS-3C, LEICI, China). The particle size distribution was examined using the hydrometer method (Bouyoucos, 1962). The WHC was measured by placing a $100-\mathrm{cm}^{3}$ cutting ring filled with thoroughly wetted soil for $24 \mathrm{~h}$ on another cutting ring filled with corresponding air-dried soil and allowed to drain for $8 \mathrm{~h}$.

Soil MBC content was measured using the chloroform fumigation extraction method (Vance et al., 1987). Briefly, a soil sample was divided into two sets $(4 \mathrm{~g}$ per set), one set was fumigated with chloroform for $24 \mathrm{~h}$ in the dark, and another set was unfumigated. Then the fumigated and unfumigated samples were extracted with $20 \mathrm{ml} 0.5 \mathrm{M} \mathrm{K}_{2} \mathrm{SO}_{4}$ in a 1:5 ratio. The extracts were filtered through $0.45 \mu \mathrm{m}$ syringe filter (Siyan Biotechnology, China) and were determined in the form of total organic $\mathrm{C}$ using a Lotix combustion TOC analyzer (Teledyne Tekmar, Mason, OH, USA). Soil MBC was calculated from the $\mathrm{K}_{2} \mathrm{SO}_{4}$-extractable organic $\mathrm{C}$ between the fumigated and unfumigated samples with a conversion factor of 0.45 . Total organic $\mathrm{C}$ in unfumigated samples represents DOC.

\subsection{Fourier-transform infrared spectroscopy analysis}

The molecular composition of SOC was characterized by Fourier transform infrared (FTIR) spectroscopy (Thermo Fisher Scientific Nicolet iS10 spectrometer, USA) according to Demyan et al. (2012). Briefly, 2 mg air-dried ground soil samples $(<0.147 \mathrm{~mm})$ were pressed into $100 \mathrm{mg}$ potassium bromide $(\mathrm{KBr})$ pellets (64 scans within the spectral range $4000-400 \mathrm{~cm}^{-1}$ at a resolution of $4 \mathrm{~cm}^{-1}$ were averaged). Band maxima at wavenumbers around 2930, 2850, 1635, 1430 and $1040 \mathrm{~cm}^{-1}$ were selected and were assigned to a range of organic functional groups (with limited mineral interference). The peak areas of these five bands were integrated using a tangential baseline from the onset to the offset of each peak, and their relative peak areas of each band were calculated to evaluate the assignments of soil C functional groups (Table S1). The ratio of the peak areas at 1635 and $2930 \mathrm{~cm}^{-1}(\mathrm{rA} 1635 / \mathrm{rA} 2930$ ratio) was defined as the resistance index and often taken as an indicator of SOC stability (Demyan et al., 2012; Ernakovich et al., 2015; Hou et al., 2019).

\subsection{Polymerase chain reaction (PCR) amplification}

The copy numbers of fungi and bacteria were measured by PCR amplification following Xia et al. (2011). DNA was extracted from $0.5 \mathrm{~g}$ soil using the NucleoSpin Soil DNA extraction kit (Macherey-Nagel, Duren, Germany). DNA extracts were stored at -20. The 16s rRNA gene, a molecular marker for bacteria, was amplified using 515F/907R (forward 5'-GTGCCAGCMGCCGCGG-3'; reverse 5'-CCGTCAATTCMTTTRAGT$\left.3^{\prime}\right)$. PCRs were performed in $20 \mu \mathrm{l}$ containing $1 \mu \mathrm{l}$ of TB Green Fast qPCR Mix, $2.5 \mu \mathrm{l}$ of each primer (10 $\mu \mathrm{M}), 1 \mu \mathrm{l}$ of DNA template and $20 \mu \mathrm{l}$ of molecular biology quality water. The amplifications were performed in a CFX-96 (Bio-Rad) following the thermal program: (1) $95^{\circ} \mathrm{C}$ for $5 \mathrm{~min}$; (2) 40 cycles at $95^{\circ} \mathrm{C}$ for $45 \mathrm{~s}$, $51^{\circ} \mathrm{C}$ for $45 \mathrm{~s}$ and $72^{\circ} \mathrm{C}$ for $60 \mathrm{~s}$; and $(3) 72^{\circ} \mathrm{C}$ for $5 \mathrm{~min}$.

The ITS gene, a molecular marker for fungi, was amplified using ITS1F/ITS2R (forward 5'CTTGGTCATTTAGAGGAAGTAA-3'; reverse 5'-GCTGCGTTCTTCATCGATGC-3'). PCRs were performed in $20 \mu \mathrm{l}$ containing $1 \mu \mathrm{l}$ of TB Green Fast qPCR Mix, $2.5 \mu \mathrm{l}$ of each primer $(10 \mu \mathrm{M}), 1 \mu \mathrm{l}$ of DNA template and $20 \mu \mathrm{l}$ of molecular biology quality water. The amplifications were performed in a CFX-96 (Bio-Rad) following the thermal program: (1) $95^{\circ} \mathrm{C}$ for $5 \mathrm{~min}$; (2) 40 cycles at $95^{\circ} \mathrm{C}$ for $45 \mathrm{~s}, 55^{\circ} \mathrm{C}$ for $45 \mathrm{~s}$ and $72^{\circ} \mathrm{C}$ for $60 \mathrm{~s}$; and $(3) 72^{\circ} \mathrm{C}$ for $5 \mathrm{~min}$. The $\mathrm{F}: \mathrm{B}$ values were calculated using the ratio of the fungal-to-bacterial gene 
copy numbers. $\mathrm{qPCR}$ cannot provide an estimation of the $\mathrm{F}: \mathrm{B}$ biomass ratio because different taxa contain an unknown number of copies of the rDNA operon in their genomes. But it provides information about the differences in the relative abundance of fungi and bacteria across soil samples (Fierer et al., 2005).

\subsection{Statistical analysis}

For all response variables, significant differences $(P<0.05)$ among water regimes in each soil and significant differences among soils in each water regime were assessed by one-way analysis of variance (ANOVA). The effects of water regimes (one constant-moisture control treatment at $60 \% \mathrm{WHC}$ and two DWC treatments of 100-20\% and 80-40\% WHC), soil treatments ( $\mathrm{OF}, \mathrm{BF}$ and $\mathrm{BF}+$ ) and their interactions on $\mathrm{C}$ decomposition, fungal-to-bacterial ratio (F:B), MBC and DOC were assessed by linear mixed models (LMM). For the LMM, soil treatment and water regime were considered as fixed factors, and sample identity was regarded as a random factor. All statistical analyses were performed using IBM SPSS Statistics 20 (IBM SPSS Inc.), and graphs were drawn using SigmaPlot 14.0 (Systat Software Inc.).

\section{Results}

\subsection{Effects of long-term field treatments on soil properties}

The 15-year $\mathrm{BF}$ and 23-year $\mathrm{BF}+$ treatments significantly decreased soil $\mathrm{C}$ and $\mathrm{N}$ contents, but did not significantly affect the $\mathrm{C} / \mathrm{N}$ ratio compared with the OF treatment $(P<0.05$, Table 1$)$. Soil clay content was lower in the $\mathrm{BF}$ and $\mathrm{BF}+$ treatments in comparison with the $\mathrm{OF}$ treatment, and soil silt content was higher in the $\mathrm{BF}+$ treatment than that of the $\mathrm{OF}$ treatment. Furthermore, the $\mathrm{BF}$ and $\mathrm{BF}+$ treatments significantly decreased soil DOC content, and the $\mathrm{BF}+$ treatment significantly reduced DOC/TC ratio compared with the OF treatment. It implies lower active $\mathrm{C}$ (DOC) content in the $\mathrm{BF}$ and $\mathrm{BF}+$ soils due to the long-term removal of plant inputs. Although soil $\mathrm{pH}$ of the $\mathrm{BF}$ and $\mathrm{BF}+$ treatments and soil $\mathrm{WHC}$ of the $\mathrm{BF}+$ treatment were significantly lower than those of the $\mathrm{OF}$ treatment, the differences among soil $\mathrm{pH}$ did not exceed 0.3 units and the differences among soil WHC did not exceed $1 \%$.

\subsection{Molecular index of SOC stability}

Fourier-transform infrared (FTIR) spectroscopy of three soils generally featured common peaks but showed different intensities (Fig. S2). The rA1635 of BF+ soil was significantly lower than that of OF soil, and the order of the rA2930 of the three soils was $\mathrm{OF}>\mathrm{BF}>\mathrm{BF}+(P<0.05$, Fig. 2a, b and Table S1). The order of the resistance index (ratio of rA1635/rA2930) of the three soils was BF $+>\mathrm{BF}>\mathrm{OF}(P<0.05$, Fig. 2c). The trend of resistance index (rA1635/rA2930) indicated that the molecular index of SOC stability (or resistance) was highest in $\mathrm{BF}+$ soil, followed by $\mathrm{BF}$ soil, and finally $\mathrm{OF}$ soil.

\subsection{Dynamics of soil carbon decomposition}

During the DWC period, soil C mineralization rates declined rapidly after the first cycle $(0-10 \mathrm{~d})$ for all water regimes, and then decreased slowly with the increasing number of DWC (Fig. 3a-c). For OF soils, cumulative soil C mineralization in 60\%, 80-40\%, and 100-20\% WHC treatments were 28.0, 27.1, and 25.7 $\mathrm{mg} \mathrm{CO} \mathrm{C}^{-} \mathrm{C} \mathrm{g}^{-1} \mathrm{SOC}$, respectively. For BF soils, cumulative soil C mineralization in 60\%, 80-40\%, and 100-20\% WHC treatments were 24.0, 22.3, and $21.6 \mathrm{mg} \mathrm{CO}-\mathrm{C} \mathrm{g}^{-1} \mathrm{SOC}$, respectively. For BF+ soils, cumulative soil $\mathrm{C}$ mineralization in $60 \%, 80-40 \%$, and $100-20 \%$ WHC treatments were $10.8,11.9$, and $12.5 \mathrm{mg} \mathrm{CO}_{2}-\mathrm{C} \mathrm{g}^{-1}$ SOC, respectively (Fig. 3d-f, Fig. 4a). Compared to the constant-moisture control treatment (60\% WHC), the 100-20\% WHC treatment decreased cumulative C mineralization of OF and BF soils by $8 \%$ and $10 \%$, respectively, but increased that of $\mathrm{BF}+$ soil by $16 \%$. The $80-40 \%$ WHC treatment did not significantly change cumulative $\mathrm{C}$ mineralization of all three soils relative to the constant-moisture control treatment (Fig. 4a and Table S2). There was also an interactive effect of water regime and soil treatment on cumulative $\mathrm{C}$ mineralization during the DWC period ( $P=0.001$, Table S3).

During the extended period, cumulative soil C mineralization of $60 \%, 80-40 \%$, and 100-20\% WHC treatments in $\mathrm{OF}$ soil were $5.0,5.9$, and $5.8 \mathrm{mg} \mathrm{CO}_{2}-\mathrm{C} \mathrm{g}^{-1} \mathrm{SOC}$, respectively. For BF soil, cumulative soil C mineralization in $60 \%, 80-40 \%$, and $100-20 \%$ WHC treatments were $5.8,3.8$, and $4.0 \mathrm{mg} \mathrm{CO}_{2}-\mathrm{C} \mathrm{g}^{-1}$ SOC, respectively (Fig. 
4b and Table S2). For BF+ soil, cumulative soil C mineralization in $60 \%, 80-40 \%$, and 100-20\% WHC treatments were 4.9, 2.0, and $1.3 \mathrm{mg} \mathrm{CO}-\mathrm{C} \mathrm{g}^{-1} \mathrm{SOC}$, respectively (Fig. 4b and Table S2). Compared to the constant-moisture control treatment, both DWC treatments (80-40\% and 100-20\% WHC) increased the cumulative $\mathrm{C}$ mineralization in OF soil but decreased it in BF and BF+ soils. Specifically, the 80-40\% WHC treatment increased $\mathrm{C}$ mineralization by $18 \%$ in $\mathrm{OF}$ soil and decreased it by $35 \%$ and $59 \%$ in $\mathrm{BF}$ and $\mathrm{BF}+$ soils, respectively; The 100-20\% WHC treatment increased C mineralization by $16 \%$ in OF soil and decreased it by $31 \%$ and $74 \%$ in BF and BF+ soils, respectively (Fig. 4b and Table S2). There was also an interactive effect of water regime and soil treatment on cumulative $\mathrm{C}$ mineralization during the extended period $(P$ $=0.001$, Table S3).

During the entire incubation period (0-90 d and 100-128 d), the 80-40\% and 100-20\% WHC treatments decreased cumulative $\mathrm{C}$ mineralization of $\mathrm{BF}$ soil by $12 \%$ and $14 \%$, respectively, but did not significantly change cumulative $\mathrm{C}$ mineralization of $\mathrm{OF}$ and $\mathrm{BF}+$ soils compared with the constant-moisture control treatment (Fig. 4c and Table S2).

\subsection{Soil MBC, DOC, and F:B ratio}

Drying-rewetting cycles had significant impacts on MBC (Fig. 5a). The $80-40 \%$ and $100-20 \%$ WHC treatments decreased the MBC content of $\mathrm{BF}$ and $\mathrm{BF}+$ soils. The $100-20 \% \mathrm{WHC}$ treatment increased the MBC content of OF soil (Fig. 5a). Soil DOC content did not differ among water regimes in all three soils (Fig. 5b).

Both $80-40 \%$ and 100-20\% WHC treatments increased F:B ratio in the BF+ soil (Fig. 5c). For constant moisture treatment at $60 \% \mathrm{WHC}, \mathrm{F}: \mathrm{B}$ ratio was lowest in the OF soil. Both MBC and DOC had a positive linear relationship with cumulative $\mathrm{C}$ mineralization during the extended period across the three soils (Fig. $6)$.

\section{Discussion}

Our results indicated that DWC had contrasting effects on the decomposition of different SOC pools. The strong DWC (100-20\% WHC) increased C release from the BF+ soil, but decreased C release from the OF and BF soils, respectively. The DWC-driven legacy effect on $\mathrm{C}$ release can last for at least $38 \mathrm{~d}$. Both the amount of microbial biomass and labile substrates contributed to this legacy effect. When considering both the extended and the DWC periods, the $80-40 \%$ and 100-20\% WHC treatments had no significant effect on SOC decomposition of $\mathrm{OF}$ and $\mathrm{BF}+$ soils, but decreased SOC decomposition of BF soil by $12 \%$ and $14 \%$, respectively, compared with the constant-moisture control treatment. Taken together, these results demonstrate the importance of DWC in modulating SOC dynamics and show the different vulnerability of different SOC pools to DWC.

\subsection{Direct effects of DWC on soil carbon mineralization}

As we hypothesized, the strong DWC with intensified drought had a stronger impact on $\mathrm{C}$ emission, showing that compared to the constant-moisture control treatment $(60 \% \mathrm{WHC})$, the $100-20 \% \mathrm{WHC}$ treatment decreased cumulative $\mathrm{C}$ mineralization during the DWC period in $\mathrm{OF}$ and $\mathrm{BF}$ soils and increased it in $\mathrm{BF}+$ soil, while the $80-40 \%$ WHC treatment did not significantly change the $\mathrm{C}$ emission of all three soils (Fig. 4a). This is because the $80-40 \%$ WHC treatment might not cause as much osmotic shock and cell lyses as the strong DWC treatment (100-20\% WHC in this study) during the drying period (Guo et al., 2012). Also, the $80-40 \%$ WHC treatment might not reach the drought threshold, and the accessible $\mathrm{C}$ from physical and physiological mechanisms after the mild drought (to $40 \% \mathrm{WHC}$ ) may not contribute much to the subsequent $\mathrm{CO}_{2}$ pulse (Barnard et al., 2020; Slessarev et al., 2020).

Although the 100-20\% WHC treatment decreased cumulative C mineralization during the entire DWC period $(0-90 \mathrm{~d})$ in $\mathrm{OF}$ and BF soils, this reduction in C emission of the 100-20\% WHC treatment only occurred in two cycles and did not significantly affect $\mathrm{C}$ mineralization in other cycles (Table S2). This result was consistent with a meta-analysis of Zhang et al. (2020), which showed that the rewetting-driven $\mathrm{CO}_{2}$ pulse can fully compensate the reduced $\mathrm{CO}_{2}$ emission during the drying period. 
For BF + soil, the 100-20\% WHC treatment increased cumulative C mineralization by $16 \%$ relative to the mean constant-moisture control treatment (Table S2). Since few active SOC in the BF+ soil was left after 25-year BF treatment and 815-d laboratory incubation, the microbial community in the BF + soil is more dominated by fungi (Fig. 5c). Fungi are considered more resistant to drought and osmotic stress than bacteria due to their multicellular hyphal networks allowing remote access to water in the soil (Barnard et al., 2013). Therefore, the reduction in $\mathrm{C}$ mineralization of the soil with more fungi $(\mathrm{BF}+$ soil) during the drying period may be smaller, and the cumulative $\mathrm{C}$ mineralization may be higher during the whole DWC period compared to the soil dominated by bacteria (OF soil). Moreover, DWC can result in a microbial composition shift toward more desiccation tolerant. For example, sensitive microorganisms die or become inactive during drought and are difficult to recover, thereby supplying substrates for more drought-tolerant surviving microorganisms (Meisner et al., 2021).

\subsection{Legacy effects of DWC on soil carbon mineralization}

Both $80-40 \%$ and 100-20\% WHC treatments increased C mineralization in OF soil but decreased it in BF and $\mathrm{BF}+$ soils compared to the mean constant-moisture control treatment during the extended period (Fig. 4b). This result indicated that the repeated DWC could cause a legacy effect on soil C mineralization, and this legacy effect can last for at least $38 \mathrm{~d}$ (including 10-d stabilization period and 28-d extended period). Butterly et al. (2011) implied that this legacy effect can last for more than $35 \mathrm{~d}$, and Li et al. (2018) believed that after 4 times of DWC, this legacy effect can last for at least $60 \mathrm{~d}$.

Compared to the mean constant-moisture treatment $(60 \% \mathrm{WHC})$, the $\mathrm{MBC}$ content at the start of the extended period (100 d) was higher in the 100-20\% WHC treatment for OF soil (Fig. 5a), while was lower in both $80-40 \%$ and 100-20\% WHC treatments for BF and BF+ soils (Fig. 5a). Moreover, there was a positive correlation between $\mathrm{MBC}$ and cumulative $\mathrm{C}$ mineralization during the extended period across the three soils (Fig. 6a). These results suggested that the changes in microbial biomass affected the legacy effect of DWC on soil C mineralization. Additionally, DOC was also positively correlated with cumulative C mineralization during the extended period across the three soils (Fig. 6b), indicating that the amount of microbial biomass and labile substrates (i.e. DOC) both contributed to the legacy effect of DWC on soil C mineralization. Notably, the fact that both MBC and DOC were positively correlated with cumulative C mineralization during the extended period is likely due to the positive linear relationship between MBC and DOC (Fig. S4). Moreover, the DWC-driven changes of soil microbial community composition may also contribute to this legacy during the extended period (Meisner et al., 2021). Together, these results are consistent with the finding of $\mathrm{Li}$ et al. (2018) who showed that the legacy effect during the extended period is attributed to the amount of plant litter (as substrate) and microbial biomass.

Taking together, both mild and strong DWC treatments had a minor effect on SOC decomposition in OF and $\mathrm{BF}+$ soils, respectively, but decreased SOC decomposition in BF soil by $12 \%$ and $14 \%$, respectively (Fig. 4c). However, it should be noted that these results need to be interpreted with caution, because we did not measure the $\mathrm{C}$ release during the stabilization period (90-100 d) and the extended period (100-128 d, 28 days) may not be long enough. Future studies can use a longer extended period and measure microbial community composition for a more mechanistic understanding of the legacy effect of DWC on soil C release.

\section{Conclusion}

This study explored the direct and legacy effects of DWC on active and relatively resistant SOC decomposition by using three soils from a long-term experimental field as well as an incubation experiment. Compared to the mean constant-moisture treatment $(60 \%$ WHC), the strong DWC treatment (100-20\% WHC) had minor effects on SOC mineralization of OF soil and BF soil in most of the cycles, but stimulated SOC mineralization of $\mathrm{BF}+$ soil. This result suggests that the relatively resistant SOC is more vulnerable to DWC than active SOC during the DWC period (0-90 d). Moreover, the DWC had a legacy effect on SOC decomposition during the extended period (100-128 d), being positive for active SOC but negative for relatively resistant SOC. Both MBC and DOC may contribute to this legacy effect. However, when both direct effect and legacy effect were considered, the strong DWC did not significantly affect the cumulative SOC decomposition of OF and 
$\mathrm{BF}+$ soils, but had a negative effect on that of $\mathrm{BF}$ soil during the entire incubation period. Taken together, our study demonstrated that DWC could create both direct and legacy effects on SOC decomposition, and these effects vary with DWC intensity and SOC pools. These findings suggest that more frequent alternating drought and rapid precipitation in the future may have a minor or even negative effect on soil $\mathrm{C}$ loss.

\section{Acknowledgements}

This work was supported by the National Natural Science Foundation of China (31770529 and 31988102), the Science and Technology Research Program of Chongqing Municipal Education Commission (KJZDK202001203, KJZD-K202003501) and the Chongqing Science and Technology Commission (cstc2020jcyjmsxmX0095, WEPKL2018ZD-05). We thank Dr. Weixin Cheng (UC Santa Cruz) for suggesting the paired old-field and bare-fallow soils and Dr. Xiuwei Zhang (Taizhou University) for providing the barefallow+incubation soils used in this study. We thank Xi Chen, Shuang Zhou, and Zhuolin Yu for laboratory assistance. We also thank Dr. Bing Yang of Chengdu Institute of Biology, Chinese Academy of Sciences for his help in statistical analysis.

\section{Declaration of Competing Interest}

The authors declare that they have no known competing financial interests or personal relationships that could have appeared to influence the work reported in this paper.

\section{References}

Barnard, R.L., Blazewicz, S.J., Firestone, M.K., 2020. Rewetting of soil: Revisiting the origin of soil $\mathrm{CO}_{2}$ emissions. Soil Biol. Biochem. 147, 107819. https://doi.org/10.1016/j.soilbio.2020.107819

Barnard, R.L., Osborne, C.A., Firestone, M.K., 2013. Responses of soil bacterial and fungal communities to extreme desiccation and rewetting. ISME J. 7, 2229-2241. https://doi.org/10.1038/ismej.2013.104

Barnard, R.L., Osborne, C.A., Firestone, M.K., 2015. Changing precipitation pattern alters soil microbial community response to wet-up under a Mediterranean-type climate. ISME J. 9, 946-957. https://doi.org/10.1038/ismej.2014.192

Barré, P., Eglin, T., Christensen, B. T., Ciais, P., Houot, S., Kätterer, T., van Oort, F., Peylin, P., Poulton, P. R., Romanenkov, V., Chenu, C., 2010. Quantifying and isolating stable soil organic carbon using long-term bare fallow experiments, Biogeosciences, 7, 3839-3850. https://doi.org/10.5194/bg-7-3839-2010

Berg, B., McClaugherty, C., 2008. Decomposition, humus formation, carbon sequestration. Plant litter. 2nd ed. Berlin Heidelberg: Springer-Verlag. https://doi.org/10.1007/978-3-030-59631-6

Birch, H.F., 1958. The effect of soil drying on humus decomposition and nitrogen availability. Plant Soil 10, 9-31. https://doi.org/10.1007/BF01343734

Blazewicz, S.J., Schwartz, E., Firestone, M.K., 2014. Growth and death of bacteria and fungi underlie rainfallinduced carbon dioxide pulses from seasonally dried soil. Ecology 95, 1162-1172. https://doi.org/10.1890/131031.1

Borken, W., Matzner, E., 2009. Reappraisal of drying and wetting effects on C and N mineralization and fluxes in soils. Glob. Change Biol. 15, 808-824. https://doi.org/10.1111/j.1365-2486.2008.01681.x

Bouyoucos, G.J., 1962. Hydrometer method improved for making particle size analyses of soils. Agron. J. 54, 464-465. https://doi.org/10.2134/agronj1962.00021962005400050028x

Butterly, C.R., Bünemann, E.K., McNeill, A.M., Baldock, J.A., Marschner, P., 2009. Carbon pulses but not phosphorus pulses are related to decreases in microbial biomass during repeated drying and rewetting of soils. Soil Biol. Biochem. 41, 1406-1416. https://doi.org/10.1016/j.soilbio.2009.03.018 
Butterly, C.R., McNeill, A.M., Baldock, J.A., Marschner, P., 2011. Changes in water content of two agricultural soils does not alter labile P and C pools. Plant Soil 348, 185-201. https://doi.org/10.1007/s11104-0110931-7

Canarini, A., Kiær, L.P., Dijkstra, F.A., 2017. Soil carbon loss regulated by drought intensity and available substrate: A meta-analysis. Soil Biol. Biochem. 112, 90-99. https://doi.org/10.1016/j.soilbio.2017.04.020

Chowdhury, T.R., Lee, J.-Y., Bottos, E.M., Brislawn, C.J., White, R.A., Bramer, L.M., Brown, J., Zucker, J.D., Kim, Y.-M., Jumpponen, A., Rice, C.W., Fansler, S.J., Metz, T.O., McCue, L.A., Callister, S.J., Song, H.-S., Jansson, J.K., 2019. Metaphenomic responses of a native prairie soil microbiome to moisture perturbations. mSystems 4, e00061-19. https://doi.org/10.1128/mSystems.00061-19

Conant, R.T., Drijber, R.A., Haddix, M.L., Parton, W.J., Paul, E.A., Plante, A.F., Six, J., Steinweg, J.M., 2008. Sensitivity of organic matter decomposition to warming varies with its quality. Glob. Change Biol. 14, 868-877. https://doi.org/10.1111/j.1365-2486.2008.01541.x

Dai, A., 2013. Increasing drought under global warming in observations and models. Nat. Clim. Change 3, 52-58. https://doi.org/10.1038/nclimate1633

Davidson, E.A., Janssens, I.A., 2006. Temperature sensitivity of soil carbon decomposition and feedbacks to climate change. Nature 440, 165-173. https://doi.org/10.1038/nature04514

de Vries, F.T., Griffiths, R.I., Bailey, M., Craig, H., Girlanda, M., Gweon, H.S., Hallin, S., Kaisermann, A., Keith, A.M., Kretzschmar, M., Lemanceau, P., Lumini, E., Mason, K.E., Oliver, A., Ostle, N., Prosser, J.I., Thion, C., Thomson, B., Bardgett, R.D., 2018. Soil bacterial networks are less stable under drought than fungal networks. Nat. Commun. 9, 3033. https://doi.org/10.1038/s41467-018-05516-7

Demyan, M.S., Rasche, F., Schulz, E., Breulmann, M., Müller, T., Cadisch, G., 2012. Use of specific peaks obtained by diffuse reflectance Fourier transform mid-infrared spectroscopy to study the composition of organic matter in a Haplic Chernozem. Eur. J. Soil Sci. 63, 189-199. https://doi.org/10.1111/j.13652389.2011.01420.x

Denef, K., Six, J., Bossuyt, H., Frey, S.D., Elliott, E.T., Merckx, R., Paustian, K., 2001. Influence of drywet cycles on the interrelationship between aggregate, particulate organic matter, and microbial community dynamics. Soil Biol. Biochem. 33, 1599-1611. https://doi.org/10.1016/S0038-0717(01)00076-1

Donat, M.G., Lowry, A.L., Alexander, L.V., O'Gorman, P.A., Maher, N., 2016. More extreme precipitation in the world's dry and wet regions. Nat. Clim. Change 6, 508-513. https://doi.org/10.1038/nclimate2941

Ernakovich, J.G., Wallenstein, M.D., Calderón, F.J., 2015. Chemical indicators of cryoturbation and microbial processing throughout an Alaskan permafrost soil depth profile. Soil Sci. Soc. Am. J. 79, 783-793. https://doi.org/10.2136/sssaj2014.10.0420

Fierer, N., Jackson, J.A., Vilgalys, R., Jackson, R.B., 2005. Assessment of soil microbial community structure by use of taxon-specific quantitative PCR assays. Appl. Environ. Microbiol. 71, 4117-4120. https://doi.org/10.1128/AEM.71.7.4117-4120.2005

Fierer, N., Schimel, J.P., 2002. Effects of drying-rewetting frequency on soil carbon and nitrogen transformations. Soil Biol. Biochem. 34, 777-787. https://doi.org/10.1016/S0038-0717(02)00007-X

Fierer, N., Schimel, J.P., 2003. A proposed mechanism for the pulse in carbon dioxide production commonly observed following the rapid rewetting of a dry soil. Soil Sci. Soc. Am. J. 67, 798-805. https://doi.org/10.2136/sssaj2003.7980

Guo, X., Drury, C.F., Yang, X., Reynolds, W.D., Zhang, R., 2012. Impacts of wet-dry cycles and a range of constant water contents on carbon mineralization in soils under three cropping treatments. Soil Sci. Soc. Am. J. 76, 485-493. https://doi.org/10.2136/sssaj2011.0315 
Harrison-Kirk, T., Beare, M.H., Meenken, E.D., Condron, L.M., 2013. Soil organic matter and texture affect responses to dry/wet cycles: Effects on carbon dioxide and nitrous oxide emissions. Soil Biol. Biochem. 57, 43-55. https://doi.org/10.1016/j.soilbio.2012.10.008

Homyak, P.M., Blankinship, J.C., Slessarev, E.W., Schaeffer, S.M., Manzoni, S., Schimel, J.P., 2018. Effects of altered dry season length and plant inputs on soluble soil carbon. Ecology 99, 2348-2362. https://doi.org/10.1002/ecy.2473

Hou, Y., Chen, Y., Chen, X., He, K., Zhu, B., 2019. Changes in soil organic matter stability with depth in two alpine ecosystems on the Tibetan Plateau. Geoderma 351, 153-162. https://doi.org/10.1016/j.geoderma.2019.05.034

IPCC, 2013. Climate change 2013: The physical science basis: Working Group I contribution to the Fifth assessment report of the Intergovernmental Panel on Climate Change. Cambridge Univ. Press.

Kim, D G., Vargas, R., Bond-Lamberty, B., Turetsky, M R., 2012. Effects of soil rewetting and thawing on soil gas fluxes: a review of current literature and suggestions for future research. Biogeosciences, 9, 2459-2483. https://doi.org/10.5194/bg-9-2459-2012

Li, J., Wang, J., Zeng, D., Zhao, S., Huang, W., Sun, X., Hu, Y., 2018. The influence of drought intensity on soil respiration during and after multiple drying-rewetting cycles. Soil Biol. Biochem. 127, 82-89. https://doi.org/10.1016/j.soilbio.2018.09.018

Lin, J., Zhu, B., Cheng, W., 2015. Decadally cycling soil carbon is more sensitive to warming than fastercycling soil carbon. Glob. Change Biol. 21, 4602-4612. https://doi.org/10.1111/gcb.13071

Meisner, A., Snoek, B.L., Nesme, J., Dent, E., Jacquiod, S., Classen, A.T., Priemé, A., 2021. Soil microbial legacies differ following drying-rewetting and freezing-thawing cycles. ISME J. 15, 1207-1221. https://doi.org/10.1038/s41396-020-00844-3

Miller, A., Schime, J., Meixner, T., Sickman, J., Melack, J., 2005. Episodic rewetting enhances carbon and nitrogen release from chaparral soils. Soil Biol. Biochem. 37, 2195-2204. https://doi.org/10.1016/j.soilbio.2005.03.021

Monger, C., Sala, O.E., Duniway, M.C., Goldfus, H., Meir, I.A., Poch, R.M., Throop, H.L., Vivoni, E.R., 2015. Legacy effects in linked ecological-soil-geomorphic systems of drylands. Front. Ecol. Environ. 13, 13-19. https://doi.org/10.1890/140269

Moore-Kucera, J., Dick, R.P., 2008. PLFA profiling of microbial community structure and seasonal shifts in soils of a Douglas-fir chronosequence. Microb. Ecol. 55, 500-511. https://doi.org/10.1007/s00248-007-9295-1

Moyano, F.E., Manzoni, S., Chenu, C., 2013. Responses of soil heterotrophic respiration to moisture availability: An exploration of processes and models. Soil Biol. Biochem. 59, 72-85. https://doi.org/10.1016/j.soilbio.2013.01.002

Muhr, J., Goldberg, S.D., Borken, W., Gebauer, G., 2008. Repeated drying-rewetting cycles and their effects on the emission of $\mathrm{CO}_{2}, \mathrm{~N}_{2} \mathrm{O}$, NO, and $\mathrm{CH}_{4}$ in a forest soil. J. Plant Nutr. Soil Sci. 171, 719-728. https://doi.org/10.1002/jpln.200700302

Najera, F., Dippold, M.A., Boy, J., Seguel, O., Koester, M., Stock, S., Merino, C., Kuzyakov, Y., Matus, F., 2020. Effects of drying/rewetting on soil aggregate dynamics and implications for organic matter turnover. Biol. Fertil. Soils 56, 893-905. https://doi.org/10.1007/s00374-020-01469-6

Parton, W.J., Schimel, D.S., Cole, C.V., Ojima, D.S., 1987. Analysis of factors controlling soil organic matter levels in Great Plains grasslands. Soil Sci. Soc. Am. J. 51, 1173-1179. https://doi.org/10.2136/sssaj1987.03615995005100050015x

Schimel, J.P., 2018. Life in dry soils: Effects of drought on soil microbial communities and processes. Annu. Rev. Ecol. Evol. Syst. 49, 409-432. https://doi.org/10.1146/annurev-ecolsys-110617-062614 
Schimel, J.P., Wetterstedt, J.Å.M., Holden, P.A., Trumbore, S.E., 2011. Drying/rewetting cycles mobilize old C from deep soils from a California annual grassland. Soil Biol. Biochem. 43, 1101-1103. https://doi.org/10.1016/j.soilbio.2011.01.008

Schmidt, M.W.I., Torn, M.S., Abiven, S., Dittmar, T., Guggenberger, G., Janssens, I.A., Kleber, M., Kögel-Knabner, I., Lehmann, J., Manning, D.A.C., Nannipieri, P., Rasse, D.P., Weiner, S., Trumbore, S.E., 2011. Persistence of soil organic matter as an ecosystem property. Nature 478, 49-56. https://doi.org/10.1038/nature10386

Semenov, V.M., Kogut, B.M., Zinyakova, N.B., Masyutenko, N. P., Malyukova, L. S., Lebedeva, T. N., Tulina, A. S., 2018. Biologically active organic matter in soils of European Russia. Eurasian Soil Sc. 51, 434-447. https://doi.org/10.1134/S1064229318040117

Shi, A., Marschner, P., 2014. Drying and rewetting frequency influences cumulative respiration and its distribution over time in two soils with contrasting management. Soil Biol. Biochem. 72, 172-179. https://doi.org/10.1016/j.soilbio.2014.02.001

Slessarev, E.W., Lin, Y., Jiménez, B.Y., Homyak, P.M., Chadwick, O.A., D’Antonio, C.M., Schimel, J.P., 2020. Cellular and extracellular C contributions to respiration after wetting dry soil. Biogeochemistry 147, 307-324. https://doi.org/10.1007/s10533-020-00645-y

Townsend, A.R., Vitousek, P.M., Desmarais, D.J., Tharpe, A., 1997. Soil carbon pool structure and temperature sensitivity inferred using $\mathrm{CO}_{2}$ and ${ }^{13} \mathrm{CO}_{2}$ incubation fluxes from five Hawaiian soils. Biogeochemistry 38, 1-17. https://doi.org/10.1023/A:1017942918708

Vance, E.D., Brookes, P.C., Jenkinson, D.S., 1987. An extraction method for measuring soil microbial biomass C. Soil Biol. Biochem. 19, 703-707. https://doi.org/10.1016/0038-0717(87)90052-6

Warren, C.R., 2016. Do microbial osmolytes or extracellular depolymerisation products accumulate as soil dries? Soil Biol. Biochem. 98, 54-63. https://doi.org/10.1016/j.soilbio.2016.03.021

Xia, W., Zhang, C., Zeng, X., Feng, Y., Weng, J., Lin, X., Zhu, J., Xiong, Z., Xu, J., Cai Z., Jia Z., 2011. Autotrophic growth of nitrifying community in an agricultural soil. ISME J. 5, 1226-1236. https://doi.org/10.1038/ismej.2011.5

Xiang, S.-R., Doyle, A., Holden, P.A., Schimel, J.P., 2008. Drying and rewetting effects on C and N mineralization and microbial activity in surface and subsurface California grassland soils. Soil Biol. Biochem. 40, 2281-2289. https://doi.org/10.1016/j.soilbio.2008.05.004

Xu, G., Chen, J., Berninger, F., Pumpanen, J., Bai, J., Yu, L., Duan, B., 2015. Labile, recalcitrant, microbial carbon and nitrogen and the microbial community composition at two Abies faxoniana forest elevations under elevated temperatures. Soil Biol. Biochem. 91, 1-13. https://doi.org/10.1016/j.soilbio.2015.08.016

Yemadje, P.L., Chevallier, T., Guibert, H., Bertrand, I., Bernoux, M., 2017. Wetting-drying cycles do not increase organic carbon and nitrogen mineralization in soils with straw amendment. Geoderma 304, 68-75. https://doi.org/10.1016/j.geoderma.2016.06.023

Yuste, J.C., Penuelas, J., Estiarte, M., Garcia-Mas, J., Mattana, S., Ogaya, R., Pujol, M., Sardans, J., 2011. Drought-resistant fungi control soil organic matter decomposition and its response to temperature. Glob. Change Biol. 17, 1475-1486. https://doi.org/10.1111/j.1365-2486.2010.02300.x

Zhang, S., Yu, Z., Lin, J., Zhu, B., 2020. Responses of soil carbon decomposition to drying-rewetting cycles: A meta-analysis. Geoderma 361, 114069. https://doi.org/10.1016/j.geoderma.2019.114069

Zhang, X., Han, X., Yu, W., Wang, P., Cheng, W., 2017. Priming effects on labile and stable soil organic carbon decomposition: Pulse dynamics over two years. PloS One 12, e0184978. https://doi.org/10.1371/journal.pone.0184978 
Zhang, X., Zhu, B., Yu, F., Cheng, W., 2021. Plant inputs mediate the linkage between soil carbon and net nitrogen mineralization. Sci. Total Environ. 790, 148208. https://doi.org/10.1016/j.scitotenv.2021.148208

Zhu, B., Cheng, W., 2013. Impacts of drying-wetting cycles on rhizosphere respiration and soil organic matter decomposition. Soil Biol. Biochem. 63, 89-96. https://doi.org/10.1016/j.soilbio.2013.03.027

Table 1 Physical and chemical properties of the soils. Values represent means of three replicates with standard deviations in parenthesis. Means within each row followed by different letters represent a significant difference $(P<0.05)$. SOC, soil organic carbon; WHC, water-holding capacity; DOC, dissolved organic carbon. OF, old-field; $\mathrm{BF}$, bare-fallow; $\mathrm{BF}+$, bare-fallow+incubation. These soils contain little inorganic carbon and soil total $\mathrm{C}$ is dominated by SOC.

\begin{tabular}{llll}
\hline Parameters & OF & BF & BF + \\
\hline Total C (\%) & $2.25(0.26) \mathrm{a}$ & $1.30(0.05) \mathrm{b}$ & $1.05(0.01) \mathrm{b}$ \\
Total N (\%) & $0.17(0.00) \mathrm{a}$ & $0.11(0.00) \mathrm{b}$ & $0.08(0.00) \mathrm{c}$ \\
$\mathrm{C} / \mathrm{N}$ & $13.6(1.6) \mathrm{a}$ & $12.3(0.4) \mathrm{a}$ & $13.3(0.4) \mathrm{a}$ \\
$\mathrm{pH} \mathrm{H}_{2 \mathrm{O}}$ & $6.74(0.01) \mathrm{a}$ & $6.50(0.03) \mathrm{b}$ & $6.52(0.02) \mathrm{b}$ \\
$\mathrm{Sand}(\%)$ & $49.1(3.3) \mathrm{a}$ & $50.1(1.5) \mathrm{a}$ & $46.1(1.1) \mathrm{a}$ \\
Silt (\%) & $31.8(2.8) \mathrm{a}$ & $36.0(2.2) \mathrm{ab}$ & $40.1(1.1) \mathrm{b}$ \\
Clay (\%) & $19.1(1.2) \mathrm{a}$ & $13.9(1.0) \mathrm{b}$ & $13.9(0.3) \mathrm{b}$ \\
WHC (\%) & $32.7(0.3) \mathrm{a}$ & $32.4(0.1) \mathrm{ab}$ & $31.7(0.3) \mathrm{b}$ \\
DOC (mg C kg-1 soil) & $187.4(5.5) \mathrm{a}$ & $96.4(5.7) \mathrm{b}$ & $72.0(2.7) \mathrm{c}$ \\
DOC/TC (\%) & $0.84(0.11) \mathrm{a}$ & $0.74(0.04) \mathrm{ab}$ & $0.69(0.03) \mathrm{b}$ \\
\hline
\end{tabular}

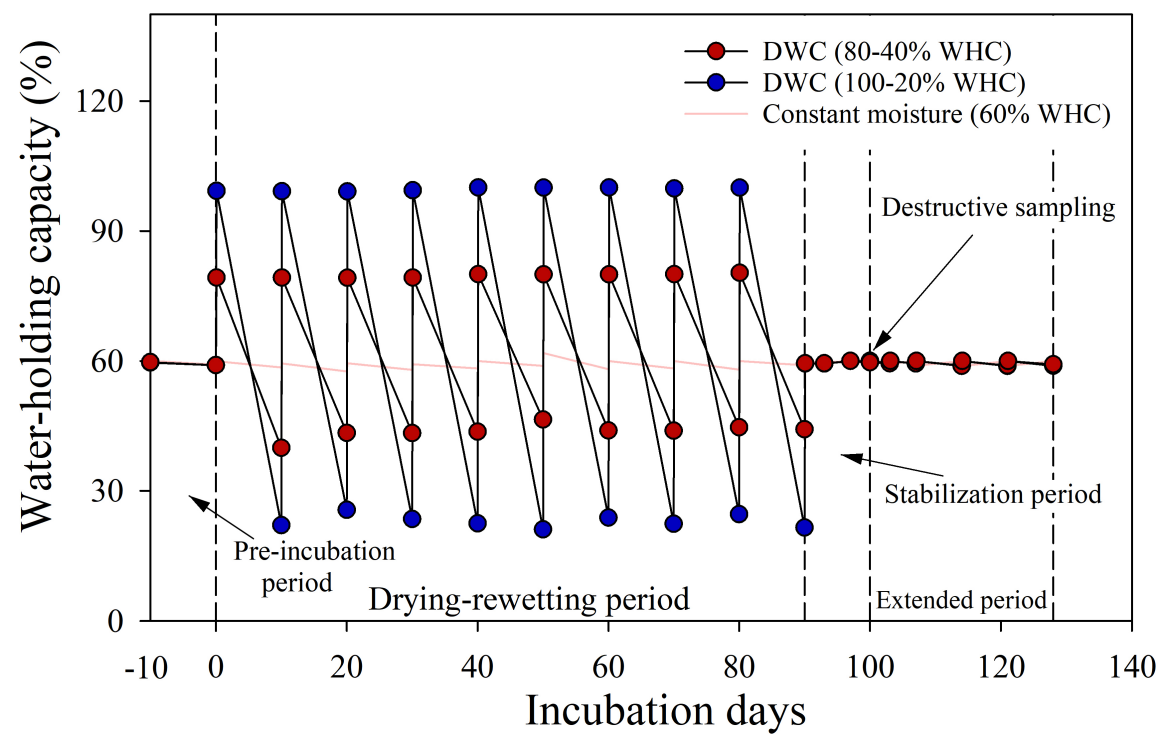



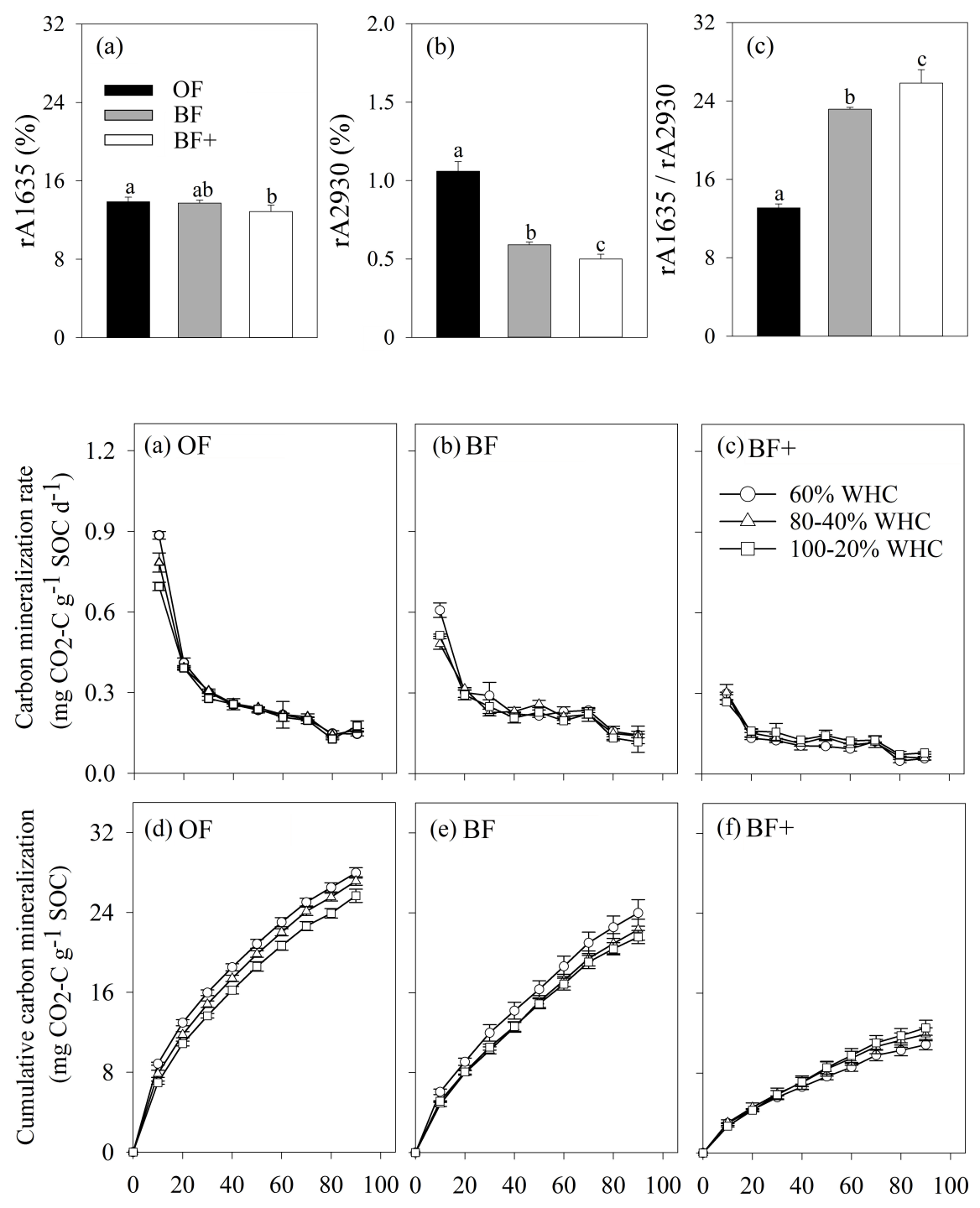

Incubation days 


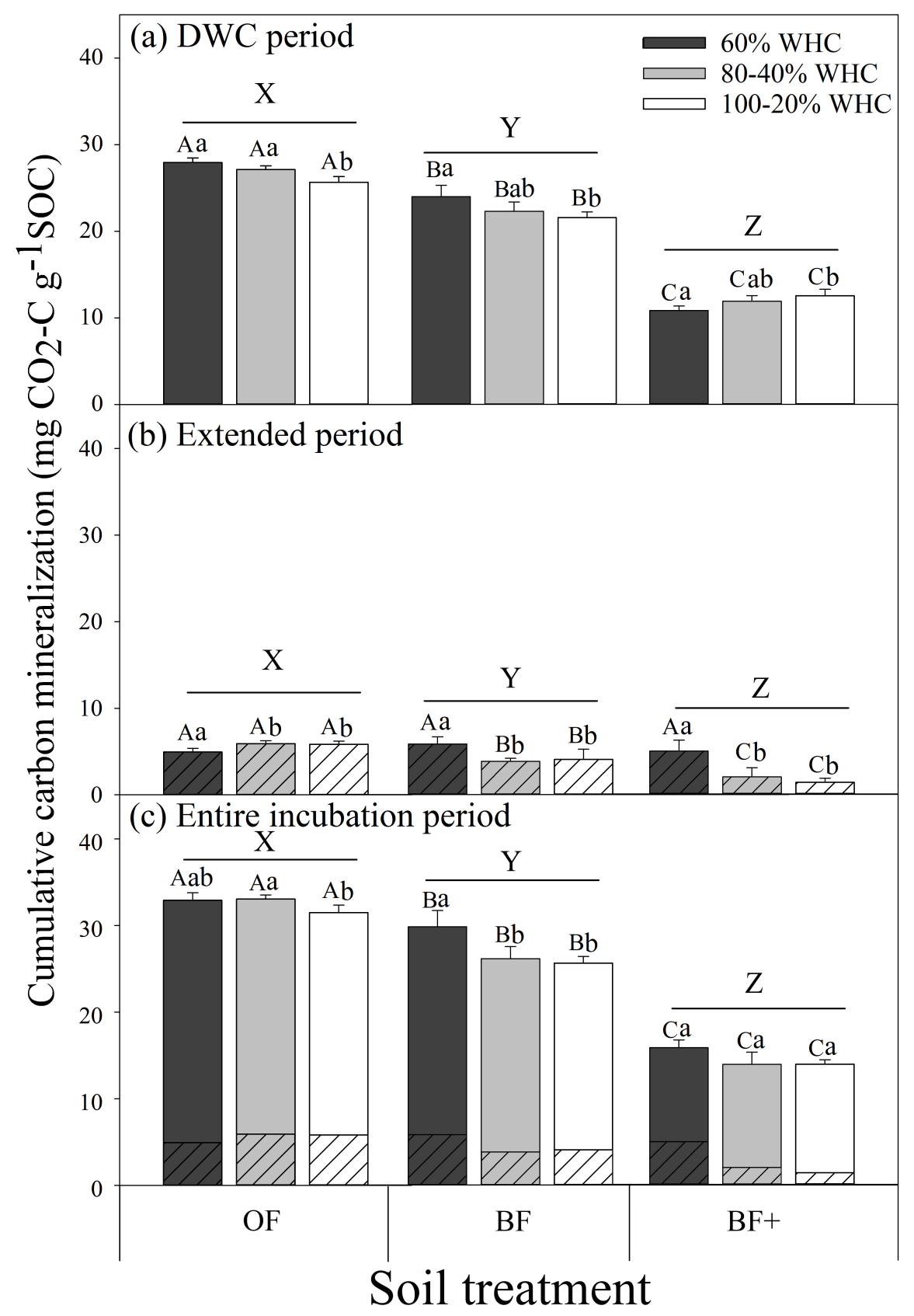




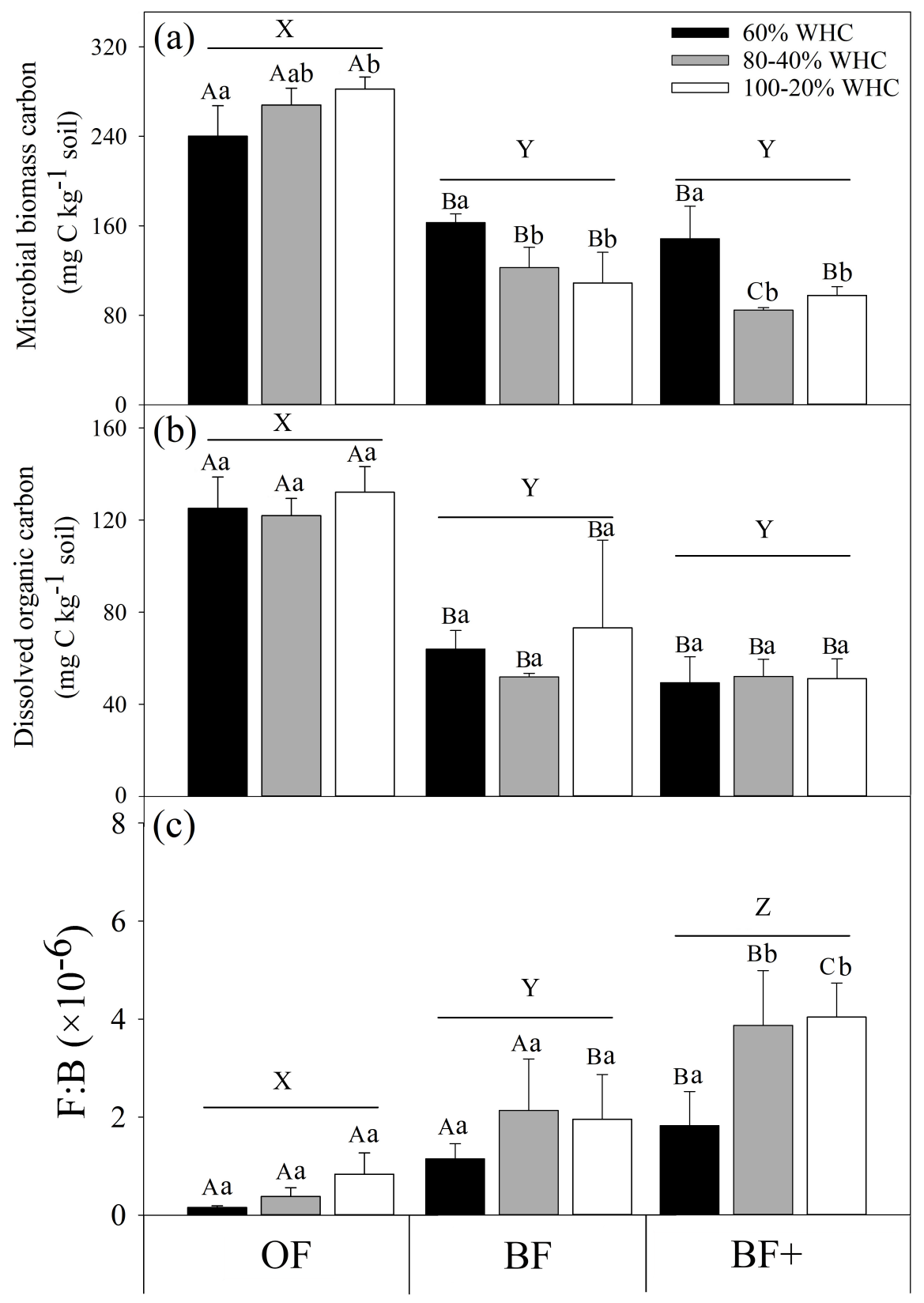

Soil treatment 


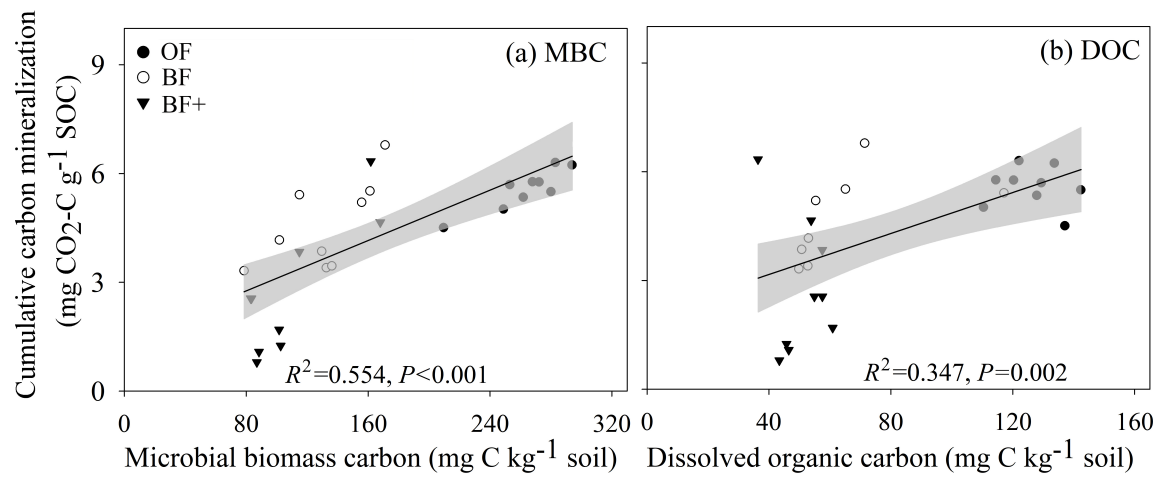

